\title{
Effect of environmental conditions on the resistance of damaged composite materials
}

\author{
Sidi Mohammed Amine Khiat, Ramdane Zenasni, Mawloud Hamdi \\ University of Mostaganem, Algeria \\ aminek@netcourrier.com,rramdane@netcourrier.com,mawloud.hamdi@univ-mosta.dz.
}

\begin{abstract}
The present paper proposes a strength model for unidirectional composites with Lin/Epoxy. The model assumes that, a central core of broken fibers flanked by unbroken fibers which are subject to stress concentrations from the broken fibers. The approach of the model consists of using a modified shear lag model to calculate the ineffective lengths and stress concentrations around fiber breaks. In this paper, we attempt to incorporate in the proposed model the unidirectional composite property variation with temperature and moisture in order to predict even composite strength degradation. Strength degradation is often seen as a result of changes in ineffective lengths at fiber breaks. Subsequently, damage to the material can be estimated at the micromechanical scale under the effect of temperature and humidity.
\end{abstract}

KEYWORDS. Unidirectional composite; Broken fibers; Micromechanics; Composite Lin/Epoxy.

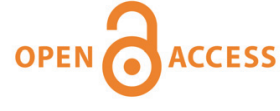

Citation: Khiat, M.A., Zenasni, R., Hamdi, M., Effect of Environmental Conditions on the Resistance of Damaged Composite Materials, Frattura ed Integrità Strutturale, 50 (2019) 595-601.

Received: 04.03.2019

Accepted: 26.07.2019

Published: 01.10.2019

Copyright: (C) 2019 This is an open access article under the terms of the CC-BY 4.0, which permits unrestricted use, distribution, and reproduction in any medium, provided the original author and source are credited.

\section{INTRODUCTION}

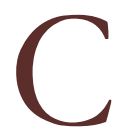

arbon fibers reinforced polymers are widely applied for mechanical and structural components because of their high specific strength and rigidity, and excellent durability. Because such reinforcing fibers are generally brittle and have a large scatter in strength, mechanical properties of composites have often been discussed from the viewpoint of materials reliability engineering. Predicting the strength of these materials from the properties of their constituents is a task which has not yet been solved for all classes of materials.

From literature, oldest models have been used for predicting the strength of polymer matrix composites are introduced by Zweben and Rosen [1, 2]. Both authors related the failure of the fiber bundles in the company of the matrix material. They used the ineffective length to estimate the tensile strength. This was based on shear lag analysis. However, this model did not consider the effects of stress concentrations in the fibers adjacent to the broken one. Phoenix et al. [3] obtained statistical strength and rupture lifetimes of unidirectional model carbon fiber/epoxy matrix micro-composites. Their model consists of seven parallel carbon fibers forming approximate hexagonal packing embedded in an epoxy matrix. Landis et al. [4] addressed the question of how to choose effective dimensions of the matrix springs connecting 
neighboring fibers by modeling the matrix by finite elements and the fibers by continuous one-dimensional springs. Their model also considered direct interactions of broken fibers with the next to nearest neighbors. Landis and McMeeking [5] later extended the work of Landis et al. [4] to account for the effects of interface sliding, axial matrix stiffness and uneven fiber positioning, on stress concentrations surrounding the broken fiber. Nedele and Wisnom [6,7] also showed that the peak stress concentration on fibers close to the broken fiber occurred slightly out of the rupture plane. Case et al. [8] proposed an entirely different analysis technique to study the stress field in a general unidirectional composite material containing fiber fractures. The model is based on approximating annular ring of fibers to represent the unbroken neighboring fibers. Multiple fiber breaks were modeled by a fiber discount methodology. Case and Reifsnider [9] addressed the problem of a penny shaped crack in the center of multiple concentric cylinders. The problem was solved by applying standard elasticity assumptions, with appropriate choice of stress functions in each constituent. This solution was applied to the problem of a fiber fracture in a unidirectional composite material by making geometrical assumptions. Foster [10] proposed a direct numerical simulations and analytic Models to predict the strength of fiber reinforced composites under tensile and flexural loading.

The main strength prediction model used in the present paper is the proposed by model Gao and Reifsnider [11]. In order to predict the unidirectional composite strength degradation, we incorporated in this model the mechanical characteristics changes. The strength degradation is a result of changes in ineffective lengths at fiber breaks and the corresponding stress concentrations in intact neighboring fibers. After the calculation of stress concentrations and ineffective lengths of composite Lin/Epoxy.

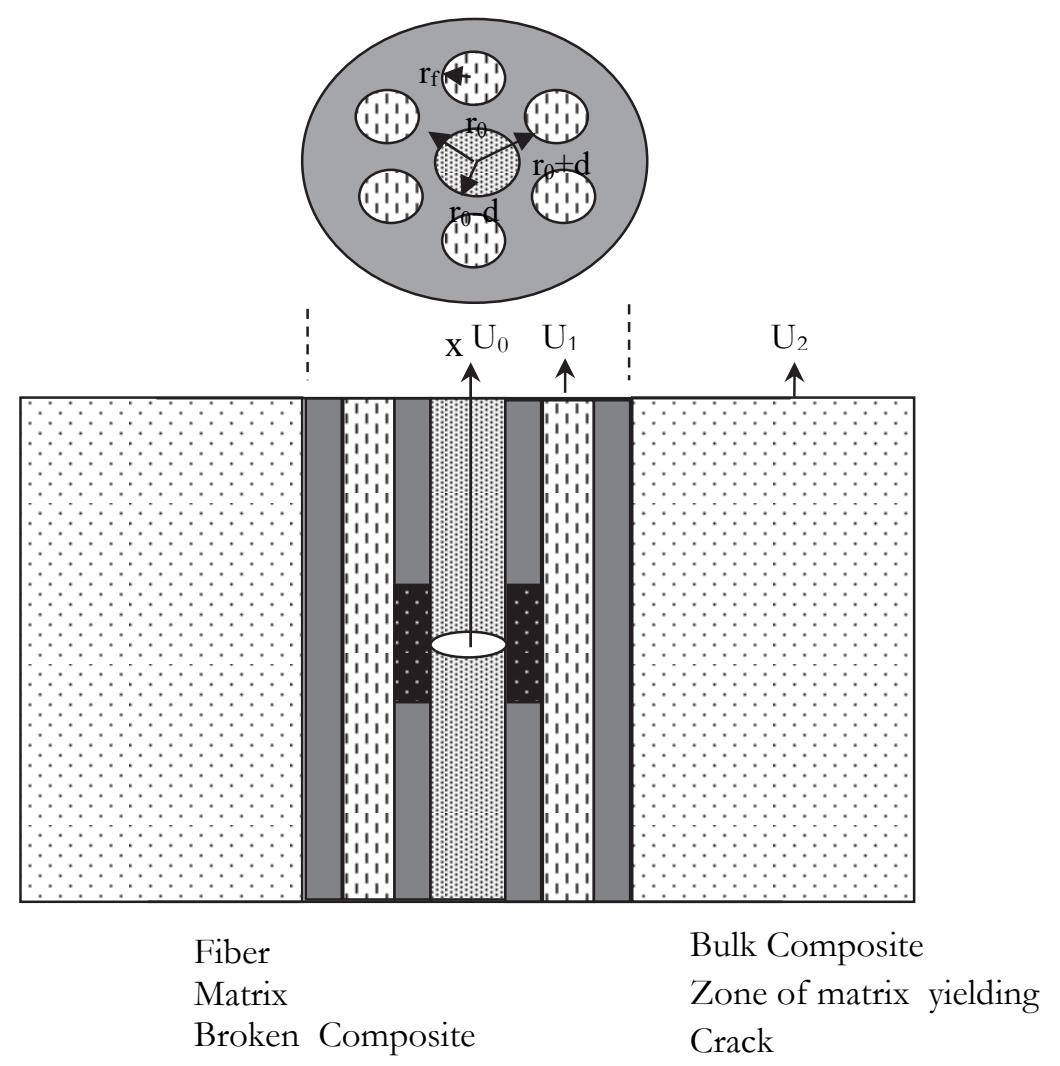

Figure 1: Schematic representation of unidirectional composite with broken fibers and adjacent regions [11].

\section{MICROMECHANICS OF TENSILE STRENGTH MODEL}

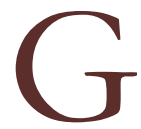

ao and Reifsnider [11], according to the model proposed by, tensile properties of fiber-reinforced composites are dependent on fiber strength and modulus, strength and chemical stability of matrix and efficiency of fiber/matrix interfacial bond in transferring loads. By introducing the micromechanical characterization with changes in temperature and moisture concentration, this model enables the prediction of changes in ineffective lengths at 
fiber breaks and the corresponding stress concentrations in intact neighboring fibers. Ineffective length $\delta$ is generally defined as the length along a fiber from the site of fiber break, necessary to regain the capability to carry full load.

In the case of Lin fibers reinforced polymers, the fiber strength and modulus are relatively insensitive to temperature and moisture concentration variation, but epoxy matrix is influenced by theses environmental conditions. Consequently, the interface fiber/matrix is con

cerned by changes in matrix properties. However, because interfacial properties are difficult to measure, the interfacial bonding strength is assumed to be directly related to the yield stress of the matrix at interface, $\tau 0$. Interfacial failure is said to occur when the shear stress of the interface reaches $\tau 0$ [12].

As illustrated in figure 1, the model considers a central core of $i$ broken fibers which are flanked by unbroken fibers which are subject to stress concentrations due to broken fibers. The unbroken fibers are, in turn, flanked by a homogenous effective material that is considered to be strained uniformly. Although the fiber bundle is not arrayed neatly, hexagonal array of fibers is assumed. It is also assumed that the influence of broken fiber is limited to a critical length, and that the stress concentration occurs to only neighboring fibers according to the arrangement. It is further assumed that broken core can be approximated by a homogeneous material with circular cross-section whose Young's modulus may be obtained by the rule-of-mixtures:

$$
E=\frac{i A_{f} E_{f}+\left[i A_{m}-\pi\left(r_{0}^{2}-\left(r_{0}-d\right)^{2}\right)\right] E_{m}}{\pi\left(r_{0}-d\right)^{2}}
$$

$\mathrm{A}$ and $\mathrm{E}$ are the area and modulus of hexagonal arrangement of $\mathrm{i}$ broken fibers flanked by unbroken fibers, respectively. In the present model, we have included the local damage by introducing a region of debonding and local plasticity where the shear strength of the matrix $\tau 0$ is multiplied by a constant $\eta$. In the region $0 \leq x \leq a$, the equilibrium equations are given by:

$$
\begin{aligned}
& i A_{f} E_{f} \beta \frac{d^{2} U_{0}}{d x^{2}}-2 \pi r_{0} \eta \tau_{0}=0 \\
& i A_{f} E_{f} \frac{d^{2} U_{1}}{d x^{2}}+2 \pi\left(r_{0}+2 d+2 r_{f}\right) \frac{G_{m}}{2 d}\left(U_{2}-U_{1}\right)+2 \pi r_{0} \eta \tau_{0}=0
\end{aligned}
$$

where $\beta$ is given as a function of geometry and fiber and matrix modulus and a is the half length of the region of debonding and plasticity. U0, U1 and U2 are tensile displacements in the three regions (figure 1).

The solutions of the differential Eqns. (2) and (3) are given below:

$$
\begin{aligned}
& U_{0}(x)=\frac{\eta \tau_{0}}{r_{0} E_{1}} x^{2}+C_{0} \\
& U_{1}(x)=C_{1}\left(e^{\lambda_{1} x}-e^{-\lambda_{1} x}\right)+\frac{2 r_{0} \eta \tau_{0}}{\left(R_{2}^{2}-r_{0}^{2}\right) E} \frac{1}{\lambda_{1}^{2}}\left(1-e^{-\lambda_{1} x}\right)+\frac{\sigma_{C}}{E_{C}} x
\end{aligned}
$$

Similarly, for the region $a \leq x \leq \infty$ where no interfacial yielding occurs, the equilibrium equations are:

$$
\begin{aligned}
& E \pi\left(r_{0}-d\right)^{2} \frac{d^{2} U_{0}}{d x^{2}}+2 \pi r_{0} \frac{G_{m}}{2 d}\left(U_{1}-U_{0}\right)=0 \\
& n_{i} A_{f} E_{f} \frac{d^{2} U_{1}}{d x^{2}}+2 \pi\left(r_{0}+2 d+2 r_{f}\right) \frac{G_{m}}{2 d}\left(U_{2}-U_{1}\right)-2 \pi r_{0} \frac{G m}{2 d}\left(U_{1}-U_{0}\right)=0
\end{aligned}
$$


The solutions of both differential equations are given by:

$$
\begin{aligned}
& U_{0}(x)=C_{2} e^{-\sqrt{\gamma_{1}} x}+C_{3} e^{-\sqrt{\gamma_{2}} x}+\frac{\sigma_{c}}{E c} x \\
& U_{1}(x)=C_{2}\left(1-\frac{\gamma_{1}}{A}\right) e^{-\sqrt{\gamma_{1}} x}+C_{3}\left(1-\frac{\gamma_{1}}{A}\right) e^{-\sqrt{\gamma_{2}} x}+\frac{\sigma_{c}}{E_{c}} x
\end{aligned}
$$

All applications are made on unidirectional graphite epoxy specimen with length L, width W and thickness T. Mechanical and geometrical characteristics of the studied considered material are given in Tabs. 1 and 2, these data are drawn from

\begin{tabular}{ccccccc}
\hline $\mathrm{E}_{\mathrm{f}}(\mathrm{GPa})$ & $\mathrm{E}_{\mathrm{m}}(\mathrm{GPa})$ & $\tau_{0}(\mathrm{MPa})$ & $\sigma_{0}(\mathrm{GPa})$ & $v$ & $\mathrm{~V}_{\mathrm{f}}$ & $\eta$ \\
27.6 & 4.2 & 25.2 & 3.10 & 0.43 & 0.53 & 1.0 \\
\hline
\end{tabular}

Table 1: Mechanical properties of Lin/epoxy specimen.

\begin{tabular}{lcccc}
\hline $1(\mathrm{~mm})$ & $\mathrm{w}(\mathrm{mm})$ & $\mathrm{t}(\mathrm{mm})$ & $\mathrm{r}_{\mathrm{f}}(\mathrm{mm})$ & $\mathrm{n}_{\mathrm{i}}$ \\
152.4 & 12.7 & 1.016 & 0.0035 & 43 \\
\hline
\end{tabular}

Table 2: Geometrical characteristics of Lin/epoxy specimen.

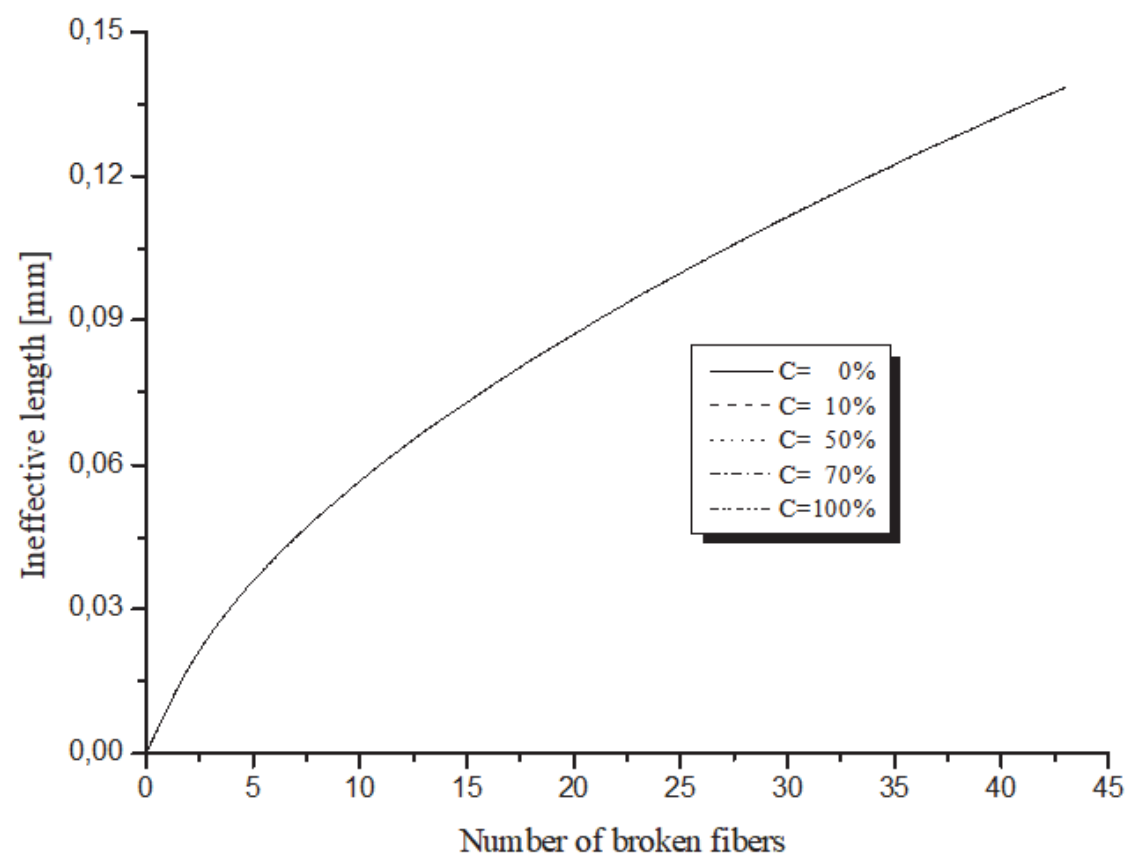

Figure 2: Evolution of the ineffective length according to the number of broken fibers with progressive variation of moisture concentration for $\mathrm{T}=20^{\circ}$ and $\sigma=0.5 \sigma_{0}$.

\section{INEFFECTIVE LENGTHS AT FIBER BREAKS}

he ineffective length is defined as the length along a fiber from the break location that it takes for the fiber to regain its ability to carry full load. Therefore it must include the zone of matrix yielding a $(\delta \geq a)$, as in constitutive laws of unidirectional composites, we distinguish three regions: a plastic, transitory and elastic zone, where $\sigma_{\mathrm{f}}$ is the 
fiber stress, $\delta$ is the ineffective length and "a "is the zone of matrix yielding. In Figs. 2 and 3, we plot the evolution of the ineffective length according to the number of broken fibers with progressive variation of moisture concentration from $0 \%$ to $100 \%$ for $\mathrm{T}=20^{\circ} \mathrm{C}$, and $120^{\circ} \mathrm{C}$, respectively. Ton figure 2 , we can clearly see a superposition of all curves representative the ineffective length. We can deduce that for low temperatures, the variation of the moisture concentration does not have any effect on the ineffective length. With the increase in the temperature to $120^{\circ} \mathrm{C}$ (Figure 3), the sensitivity of the ineffective length to the variation of the moisture concentration becomes more and more significant. At $\mathrm{T}=120^{\circ} \mathrm{C}$, the ineffective length for 43 broken fibers which is $0.11 \mathrm{~mm}$ for $\mathrm{C}=0 \%$ become $0.10 \mathrm{~mm}$ for $\mathrm{C}=100 \%$.

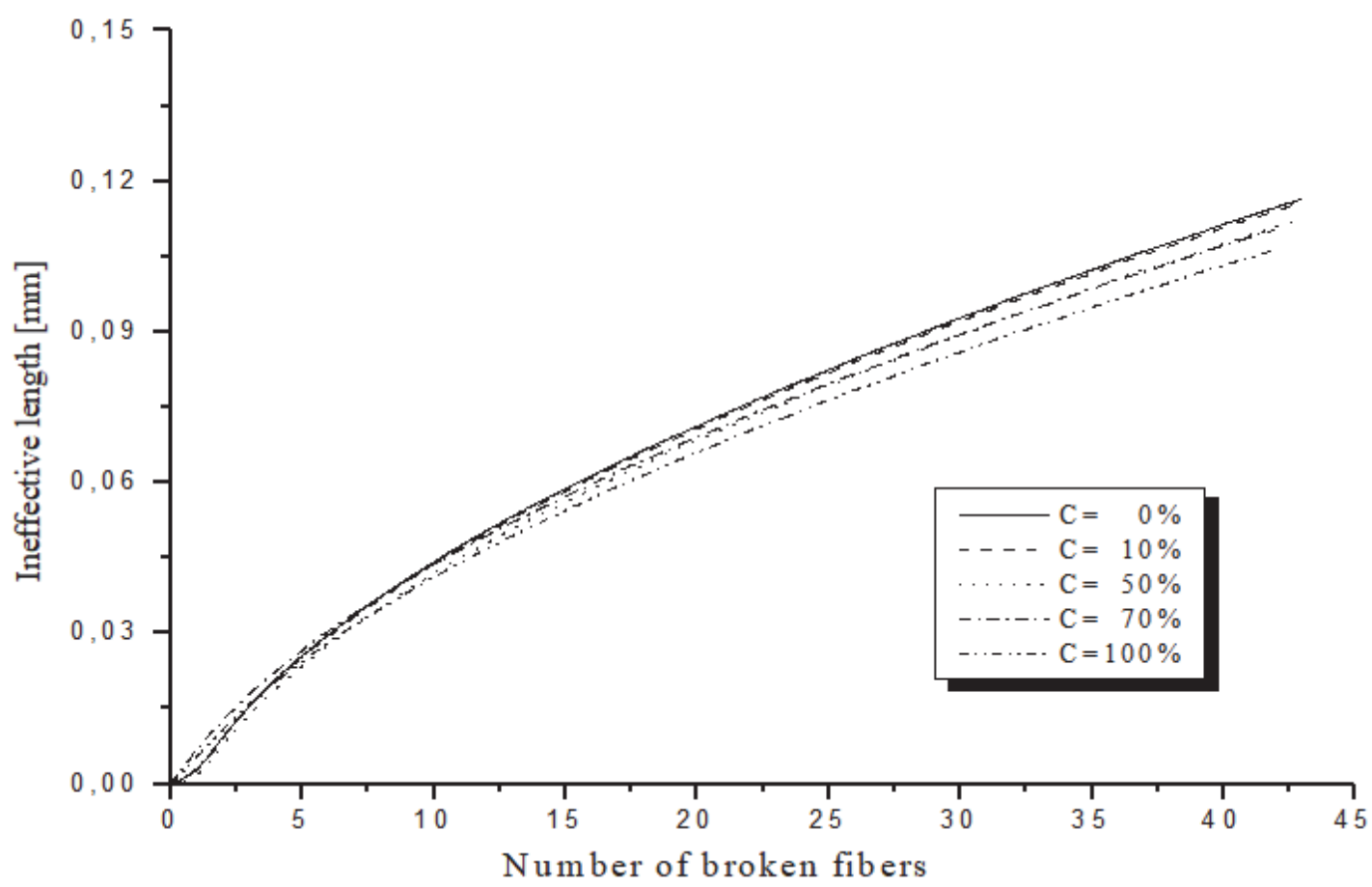

Figure 3: Evolution of the ineffective length according to the number of broken fibers with progressive variation of moisture concentration for $\mathrm{T}=120^{\circ}$ and $\sigma=0.5 \sigma_{0}$.

\section{EVOLUTION OF STRESS CONCENTRATIONS}

$\mathrm{U}$

nder hygrothermal loading of unidirectional composites, the influence of interfacial adhesion on the tensile strength is mandatory effects on stress concentration in the fibers adjacent to broken fibers, and critical length of broken fibers. Since the matrix is very sensitive to the variation in temperature, the adherence at interface region between fibers and matrix becomes very weak; thus the phenomenon of debonding appears, leading to the break of fibers. When a fiber breaks in the composite, there is a region of influence generated around the end of the broken fiber where a stress concentration exists. On the other hand, the load can be transferred back into the broken fiber with a shear stress at the fiber/matrix interface.

To illustrate the effect of environmental conditions on the degradation of interfacial region surrounding the broken fibers, we plot in (Figs. 4 and 5) the evolution of the stress concentrations according to the number of the broken fibers with progressive variation of moisture concentration from $0 \%$ to $100 \%$ for $\mathrm{T}=20^{\circ} \mathrm{C}$ and $120^{\circ} \mathrm{C}$, respectively. In both figures, the stress concentrations become more significant with the increase in the number of broken fibers. Thereafter, this stress concentration becomes relatively stable if the number of fibers becomes very large. For low temperatures, the effect of the moisture concentration on the stress concentration is almost negligible (Fig. 4). The effect of the moisture concentration becomes increasingly significant with the increase in the temperature to $120^{\circ} \mathrm{C}$ (Fig. 5). At $\mathrm{T}=120^{\circ} \mathrm{C}$, a clear distinction appears between all curves; for example, with 43 broken fibers, the stress concentration varies from 1.17 for $\mathrm{C}=0 \%$ to 1.20 for $\mathrm{C}=100 \%$. 


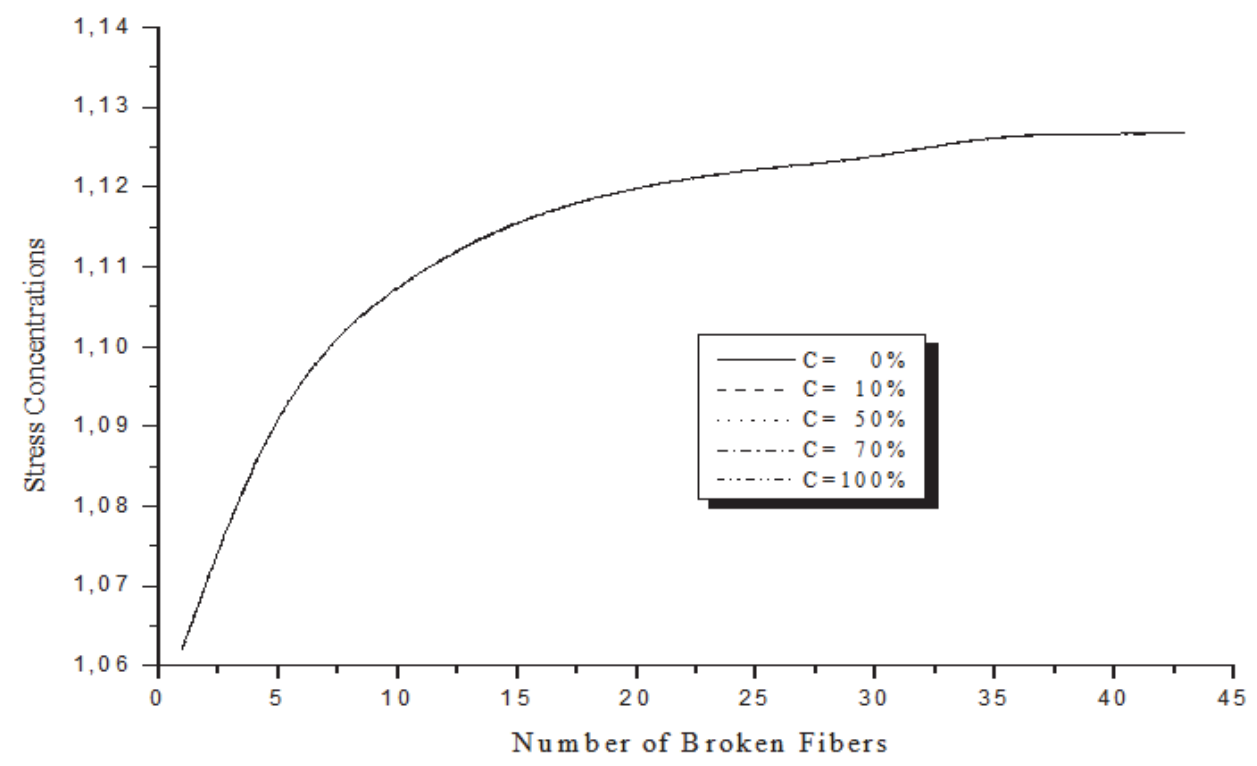

Figure 4: Evolution of the stress concentrations according to the number of broken fibers with progressive variation of moisture concentration for $\mathrm{T}=20^{\circ}$ and $\sigma=0.5 \sigma_{0}$.

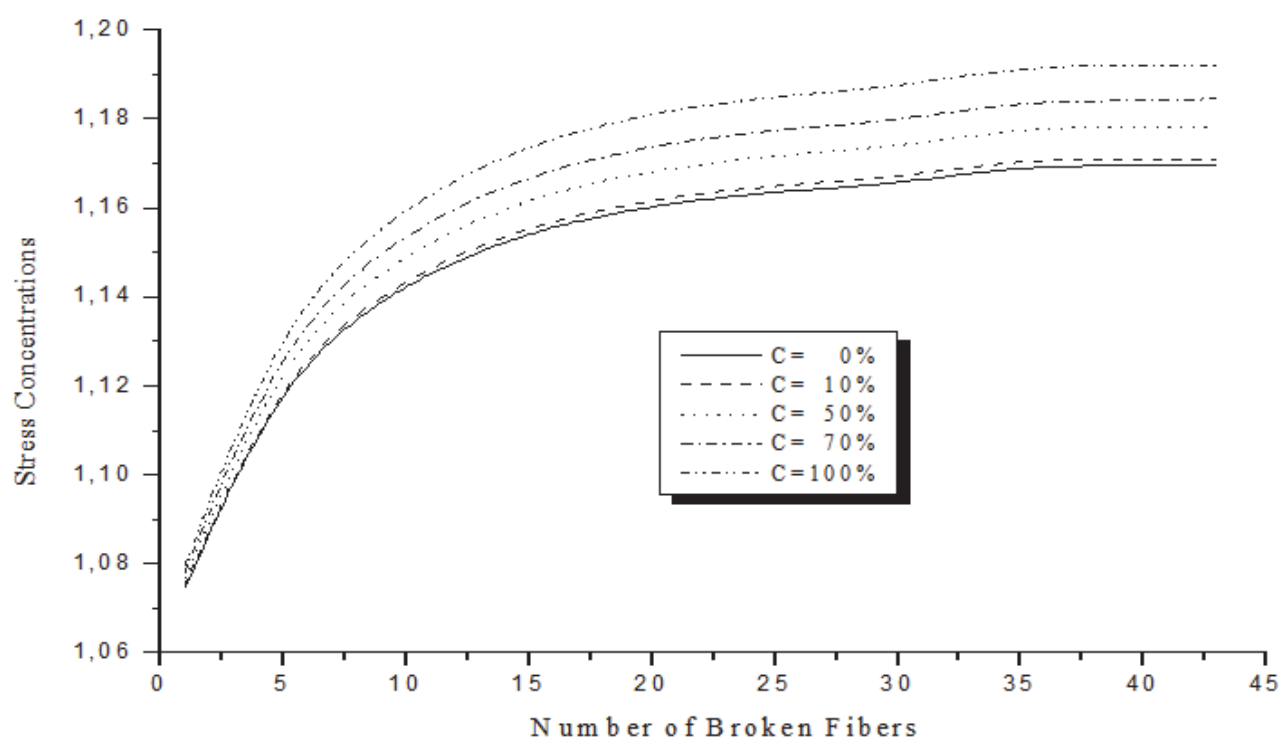

Figure 5: Evolution of the stress concentrations according to the number of broken fibers with progressive variation of moisture concentration for $\mathrm{T}=120^{\circ}$ and $\sigma=0.5 \sigma_{0}$.

\section{CoNCluSIONS}

he aim of this work is to develop a better understanding of how temperature and moisture may affect the stress concentration of unidirectional composite materials, in terms of the number of broken fibers. By introducing the micromechanical characterization with changes in temperature and moisture concentration, the proposed model enables the prediction of changes in stress concentrations in the neighboring fibers. Consequently, the interface fiber/matrix is concerned by changes in the matrix properties because the stress is transferred to the neighboring fibers. If the surrounding matrix becomes less stiff, the ineffective length becomes larger and the fiber fractures regions will interact more easily and may connect together to cause complete failure. 


\section{REFERENCES}

[1] Rosen, B.W., 1964. Tensile failure of fibrous composites. AIAA J. 2, 1985-1991. DOI: 10.2514/3.2699.

[2] Zweben, C., 1968. Tensile failure of fiber composites. AIAA J. 6, 2325-2331. DOI: 10.2514/3.4990.

[3] Phoenix, S. L., Schwartz, P. (1988). Statistics for the Strength and Lifetime in Creep-Rupture of Model Carbon/Epoxy Composites, Compos Sci Technol, 32, pp. 81-120. DOI: 10.1016/0266-3538(88)90001-2.

[4] Landis, C. M., McGlockton, M. A. (1999). An Improved Shear Lag Model for Broken Fibers in Composite Materials, J Compos Mater, 33(7), pp. 667-680. DOI: 10.1177/002199839903300704.

[5] Landis, C. M., McMeeking, R. M. (1999). Stress Concentrations in Composites with Interface Sliding, Matrix Stiffness, and Uneven Fiber Spacing Using Shear Lag Theory, Int J Solids Struct, 36, pp. 4333-4361. DOI: 10.1016/S0020-7683(98)00193-0.

[6] Nedele, M. R. (1994). Three-dimensional Finite Element Analysis of the Stress Concentration at a Single Fiber Break, Compos Sci Technol, 51, pp. 517-524. DOI: 10.1016/0266-3538(94)90084-1.

[7] Nedele, M. R., Wisnom, M. R. (1994). Stress Concentration Factors Around a Broken Fiber in a Unidirectional Carbon Fiber-Reinforced Epoxy, Composites, 27, pp. 549-557. DOI: 10.1016/0010-4361(94)90183-X.

[8] Case, S. W., Carman, G. P., Lesko, J. J., Fajardo, A. B., Reifsnider, K. L., (1995). Fiber Fracture in Unidirectional Composites, J Compos Mater, 29(2), pp. 208-228. DOI: 10.1177/002199839502900205.

[9] Case, S. W., Reifsnider, K. L. (2006). Micromechanical of Fiber Fracture in Unidirectional Composite Materials, Int J Solids Struct, 33(26), pp. 379-381. DOI: 10.1016/0020-7683(95)00214-6

[10] Foster, G. C. (2008). Tensile and Flexure Strength of Unidirectional Fiber-Reinforced Composites: Direct Numerical Simulations and Analytic Models, Master of Science in Engineering Mechanics, Virginia Polytechnic Institute and State University.

[11] Gao, Z., Reifsnider, K. L. (1993). Micromechanics of Tensile Strength in Composite Systems, Composite Materials: Fatigue Fract, Fourth Volume, ASTM STP 1156, pp. 453-470. DOI: 10.1520/STP24745S.

[12] Curtin, W. A. and Takeda, N. (1998). Tensile strength of fiber-reinforced composites: II. Application to polymer matrix composites, J Compos Mater., 32, pp. 2060-2081. 